\title{
How the Department of the Navy Translates Space Support Requirements into Program Plans
}

\author{
Captain Dwight Denson, U. S. Navy \\ Assistant Commander for Space Technology, \\ Space and Naval Warfare Systems Command, Washington, D.C. 20363
}

(202) $767-9600$

\section{NAVAL ACTIVITIES IN SPACE}

The Department of the Navy translates its requirements for support from space into a viable set of programs which are both cost effective and met the needs of the Navy's operational commanders. The process by which Navy accomplishes this planning function is the topic of this paper.

It is not generally known that, beginning in the late 1950's, Navy was -- and continues to this day -- a major participant in national security space activities. For instance, Navy designed and launched the first spacebased navigation system, TRANSIT, as well as some of our earliest surveillance and communications satellites. Navy also developed the technology used today in NAVSTAR Global Positioning System (GPS), and the concepts for using national reconnaissance systems to support combat operations from space.

While Navy is not assigned a principal mission in space, naval forces -- both Navy and Marine Corps -- are the largest users of space-borne command, control, and surveillance assets. As a result, our efforts are directed primarily at leveraging others' space systems, and our investment funding reflects this fact, as will be demonstrated.

Navy's space program emphasizes a robust technology effort, along with significant support to national agencies and other services. Today, we are building the UHF Follow-On System, serving tactical UHF communications needs of naval and Air Force operational users, and GEOSAT Follow-On, which will provide environmental data required by the Fleet.

In addition to technology, Navy participates in Navy-unique space system acquisition and naval and joint operations support, including: training; user interface; and support to space operations such as performing alternate satellite control, and operating the nation's Space Surveillance "fence" and the Space Operations Center at Point Magu, California. Navy also continues to participate in development and acquisition of national intelligence space systems.

\section{INITIAL GUIDANCE}

Today, the Department of the Navy's space support requirements are firmly founded in Department of Defense and Navy policy directives. Guidance from these directives is translated into funded programs in the Navy's Program Objectives Memorandum, or "POM," which is the Department's programmatic plan for a given fiscal year. Policy documents essential to the process include: Office of the Secretary of Defense ("OSD") annual Defense Planning Guidance; Department of the Navy's "Forward...From the Sea" white paper; and the Department of the Navy's recent Space Policy. "Forward....From the Sea" builds upon Navy's 1992 strategic concept which emphasizes the need for exploitation of space-based capabilities to provide vital support for naval force commanders. In implementing this broad strategy, the Department of the Navy's Space 
Policy, issued in 1993, clearly articulates that space is vital to the success of the maritime mission, and sets the stage for full naval participation in military space matters.

As a major team player in the current emphasis on joint littoral warfare, Navy also considers applicable aspects of several related recent Navy and joint policy initiatives. These include: navy's "COPERNICUS" Architecture for command, control, communications, computers and intelligence ("C4I"); the JCS Chairman's "C4I for the Warrior" which establishes goals for joint operations; the evolving plans and programs for space-related capabilities of the other military Services; and the capabilities being developed in industry and academia, both here and abroad. All of the foregoing enter into the Department's Joint Mission and Support Assessment process.

\section{SPACE ACQUISITION REORGANIZATION}

Related to the assessment process is the fact that, as may of you know, Congress recently directed DoD to consolidate the research, development, and acquisition of national security space programs. This process is now underway. Air Force is designated the primary acquisition authority for most space programs, while Navy will be able to develop capabilities to satisfy naval-unique requirements. UHF Follow-On is an example of such a program, currently managed by Navy. A Deputy Under Secretary of Defense for Space office has been established, together with a DoD Space Architect position. Naval personnel serve on each of these staffs, and Navy has been assigned executive-level seats on the Joint Space Management Board.

In order to provide coordinated Navy support to these joint efforts, Navy recently established its own Naval Space Board. Navy and marine Corps space-related offices and activities all have a seat on this Board, which is chartered to provide advice and counsel to the
Department's leadership on the full spectrum of space, and space-related programs which support Navy's roles, mission and functions. Oversight of space-related personnel career paths and joint assignments is an example of one of the Board's primary functions.

\section{NAVAL SPACE ACQUISITION PROCESS}

The process for naval space-related acquisition programs is governed by law, and follows a path similar to the other military services. Funding and technical guidance from the Office of Management and Budget (OMB), and from OSD, flows down through the Navy Deputy Assistant Secretary for Space at the Pentagon, to the Space and Naval Warfare and Marine Corps Systems Commands and Space Program Executive Office, as well as Navy's Center for Space Technology at the Naval Research laboratory. Navy is well equipped and organized to provide the technology and the hardware for unique naval mission requirements, and to support our joint efforts in space.

Establishing funding priorities and levels for Navy's space research, development and acquisition efforts is founded in the Joint Mission Assessment process, established for the Chief of Naval Operations a few years ago. Building blocks considered during development of Navy's POM are the four key operational capabilities of C4I, Battlespace Dominance, Power Projection, and Force Sustainment. Also considered are the seven Joint Mission Areas of Joint Strike, Joint Littoral, Joint Surveillance, Joint Space and Electronic Warfare ("SEW"), Strategic Sealift, Strategic Deterrence, and Forward Presence. Space is incorporated into five of the six Support Warfare Tasks which include SEW, Intelligence, Logistics, C3, Ocean Surveillance, and Special Warfare, as each contributes to joint warfighting. 
Major elements of these six spacerelated Support Tasks include:

- Joint Surveillance: Indications and warning; operational employment; and battle damage assessment.

- C3: Command; control; communications; and computers.

- SEW: Operational security; signals management; counter $\mathrm{C} 3$; and electronic combat.

- Special Warfare: Support to naval operations.

- Intelligence: Timely and readily accessible information.

An intrinsic element of "SEW," and gaining increasing attention in Navy programmatic discussions, is the recentlydefined concept of "Information Warfare." This is something which Navy has been doing all along but, as information processing capabilities expand exponentially, Navy, and DoD for that matter, must be prepared to protect its assets fully, and to attack others' rapidly and effectively when directed.

Navy's Joint Mission and Support Assessment (JMA) process consists of: an annual package of computer simulations; wargames such as the "global" game at the Naval War College in Newport; independent analyses; and Subject Matter Expert seminars. Inputs to this process are received from naval operational commanders, the Joint Staff, current issues, program alternatives, and emerging space technology. The emphasis now clearly is on "joint," and Navy is a full participant in the Joint Requirements Oversight Council, which is chaired by the JCS Vice Chairman, as well as the new Joint Space Management Board. Warfighter requirements are expressed both via the unified commanders to the JCS, and through the Navy chain of command to the Chief of Naval Operations (CNO).

JMA teams are chaired by flag and general officers who provide warfare and programmatic experience and expertise. Their iterative deliberations continuously refine and address operational requirements, evolving naval strategies, doctrine, and fiscal realties. Their product is an Integrated Investment Strategy, the result of a formal Investment Balance Review conducted y the Navy's Resource and Requirements Review Board, ensuring future readiness and ability to execute all naval missions, such as support from space. The product at this point is the Navy's POM, which properly reflects warfighting requirements, is fully funded, and is balanced across all warfare and support areas. Each cycle's POM then is presented to OSD by the Secretary of the Navy, for OSD and OMB reconciliation as the president's Budget takes shape.

\section{NAVAL. SPACE TECHNOLOGY}

A primary naval contribution to the national security space effort is technology development. This is of especial interest to the office of Navy's Space Technology Program (PD-40); particularly those aspects of this process which address space support for naval missions. Naval Laboratories, systems commands, Naval Space Command, the PEO for Space, and other Services, non-DoD government activities, industry and academia all comprise the "push" side of the Naval Space "Technology Equation." One vehicle for technology insertion, produced by the Office of Naval Research (ONR) and the Naval Research Laboratory, is the periodic "Space Technology Plan." This Plan is for Navy internal use as well as input to the Joint Directors of Laboratories "Defense Area Technology Plans," and OSD's "Science and Technology Master Plan." Following assessment of emerging technologies from Navy, DoD, academic and industrial research and development efforts, ONR promotes those technologies most promising for future investigation and potential development. 
On the "Requirements Pull" side of the Technology Equation, the Fleet Commandersin-Chief express their space-related needs directly to the $\mathrm{CNO}$, and indirectly through the Unified Commanders to the JCS Joint Requirements Oversight Council, for inclusion in the inputs offered by the Navy Secretary and OSD to the annual Defense Resource Requirements Board. A balanced, appropriately prioritized, space technology plan is the objective of this ongoing naval space technology effort. Of highest importance to the Fleet these days, for instance, is a high data rate, wide bandwidth, integrated command and control system, incorporating satellite communications as a key element.

Other specific technologies currently under investigation at Navy and its supported laboratories include: Superconductivity; passive millimeter wave sensors; cryogenic infraredcomponent cooling; synthetic aperture radar developments; and ATM/SONET advances. Space systems and tactical exploitation equipment currently in development under the leadership of SPAWARSYSCOM and the PEO for Space include: UHF Follow-On satellite communications program; a new version of tactical equipment for field unit reception of national sensor data; and Navy's contributions to the GBS and Joint MILSTAR programs. Space systems now, or soon to be, on-orbit, or which are supporting naval activities, include the following major programs: Fleet SATCOM/LEASAT; GEOSAT; DMSP; MILSTAR; TRANSIT and GPS navigational aids; the system which provides surveillance of space objects, managed by Navy's Space Command at Dahlgren, Virginia, and includes a "space fence" across the southern U.S.; as well as full support to national security space programs.
SUMMARY

The Department of the Navy, as an equal partner in joint military efforts to exploit space-based capabilities for support of its forces at sea and ashore, has developed an effective process for ensuring that its space support reflects the emerging needs of the warfighting Fleet commanders -- during routine peacetime operations right through crises into regional wars -- as well as the most promising technologies which the nation's combined research and development efforts have to offer. Translating those needs, and using those technologies, in developing effective space systems in a timely and cost efficient manner, is the challenge posed to Navy's Space and Naval Warfare Systems Command and PEO for Space ... a challenge repeatedly met with capabilities which permit the Fleet to fight smarter, quicker, more knowledgeably, and well inside any potential enemy's "decision loop." 
Captain Denson has twenty-five years operational, technical, and managerial experience in naval aviation, command \& control, space systems, acquisition, test \& evaluation, aircraft engineering, and program management. Captain Denson was assigned as Director, Naval Space Technology Program in July 1995. Previously, he had served as Deputy Director for Special Programs, Office of Naval Research. He also served as Senior Naval Aviator in the Naval Aviation Science \& Technology Office. From 1991-1994 Captain Denson was the Deputy Director for Plans \& Policy, Naval Space Technology Program, SPAWAR 40.

His principal technical tours of duty prior to then were at the Naval Air Systems Command and with Commander, Operational \& Technical Evaluation Force. His operational assignments included deployments in USS SARATOGA (CV-60), and with Carrier Airborne Early Warning Squadron 115 , embarked in USS MIDWAY (CV-41), where he participated in combat deployments in North Vietnam, 1972-1973.

Captain Denson's education and training includes a B.S. degree from the $U$. S. Naval Academy, a M.S. degree from the U.S. Naval Postgraduate School, and the Program Manager's Course at Defense Systems Management College. His awards include the Defense Meritorious Service Medal, Meritorious Service Medal, Joint Service Commendation Medal, Navy Commendation Medal, Air Medal (3), and various unit commendation and campaign ribbons. 


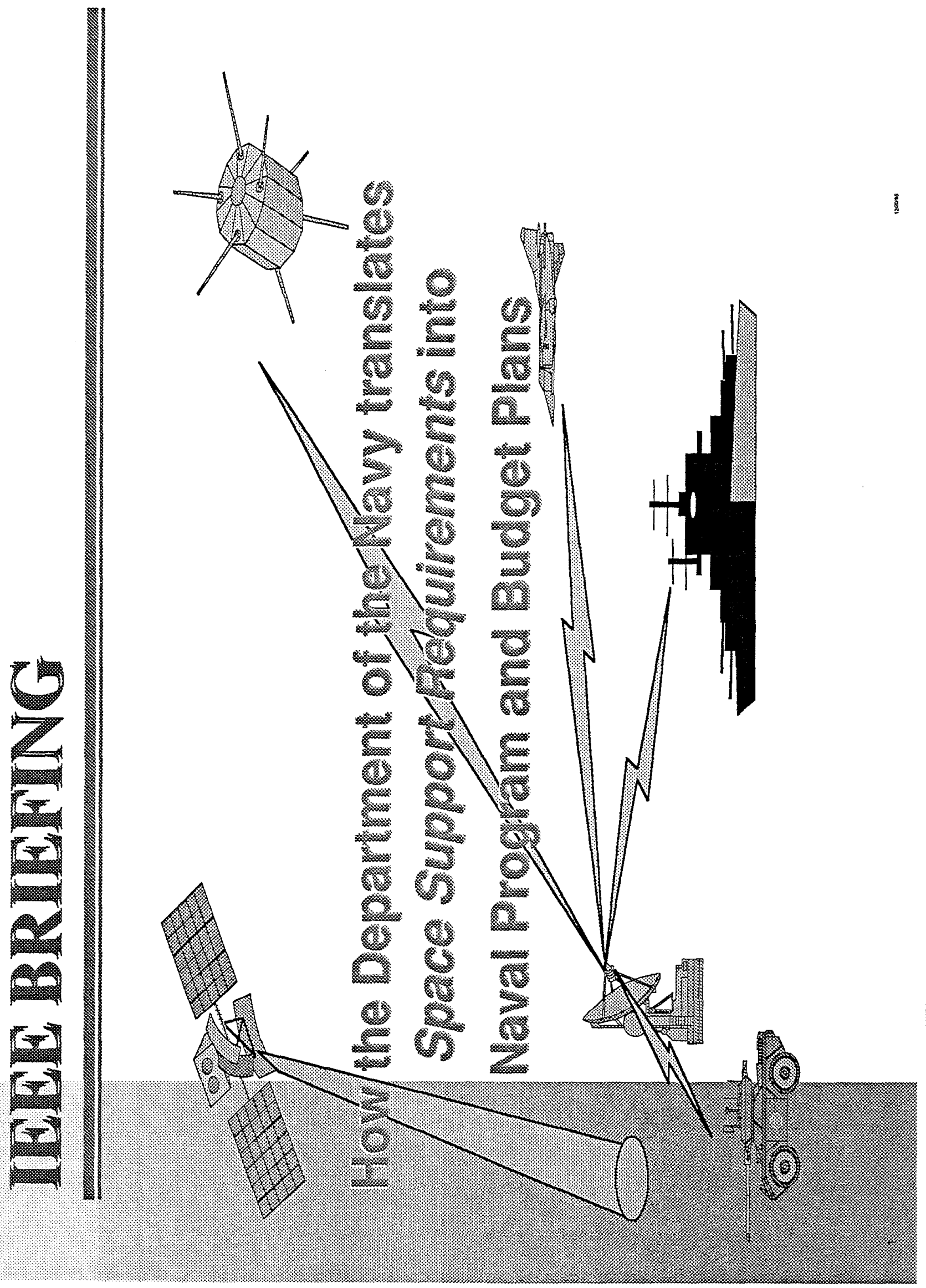




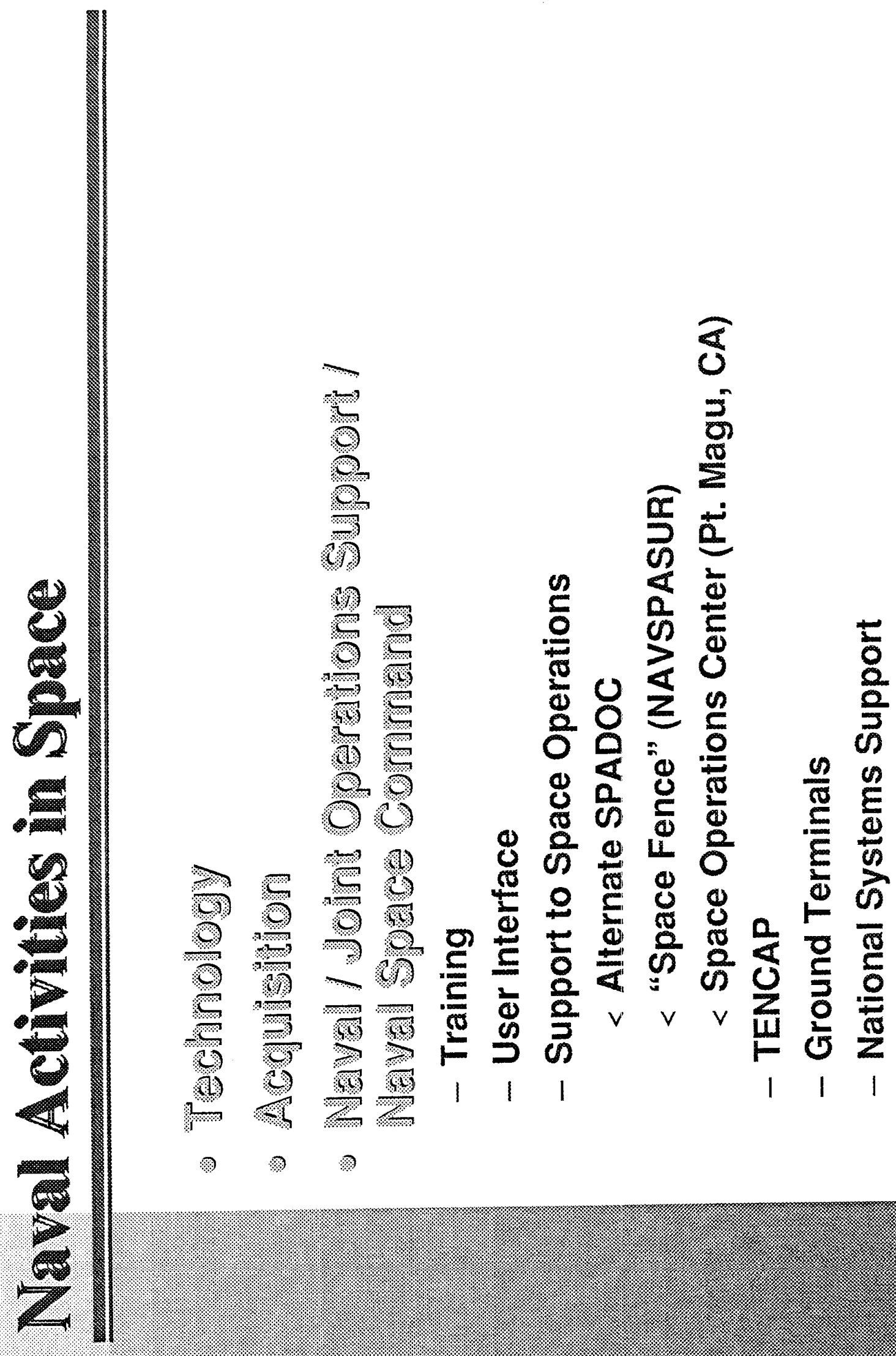




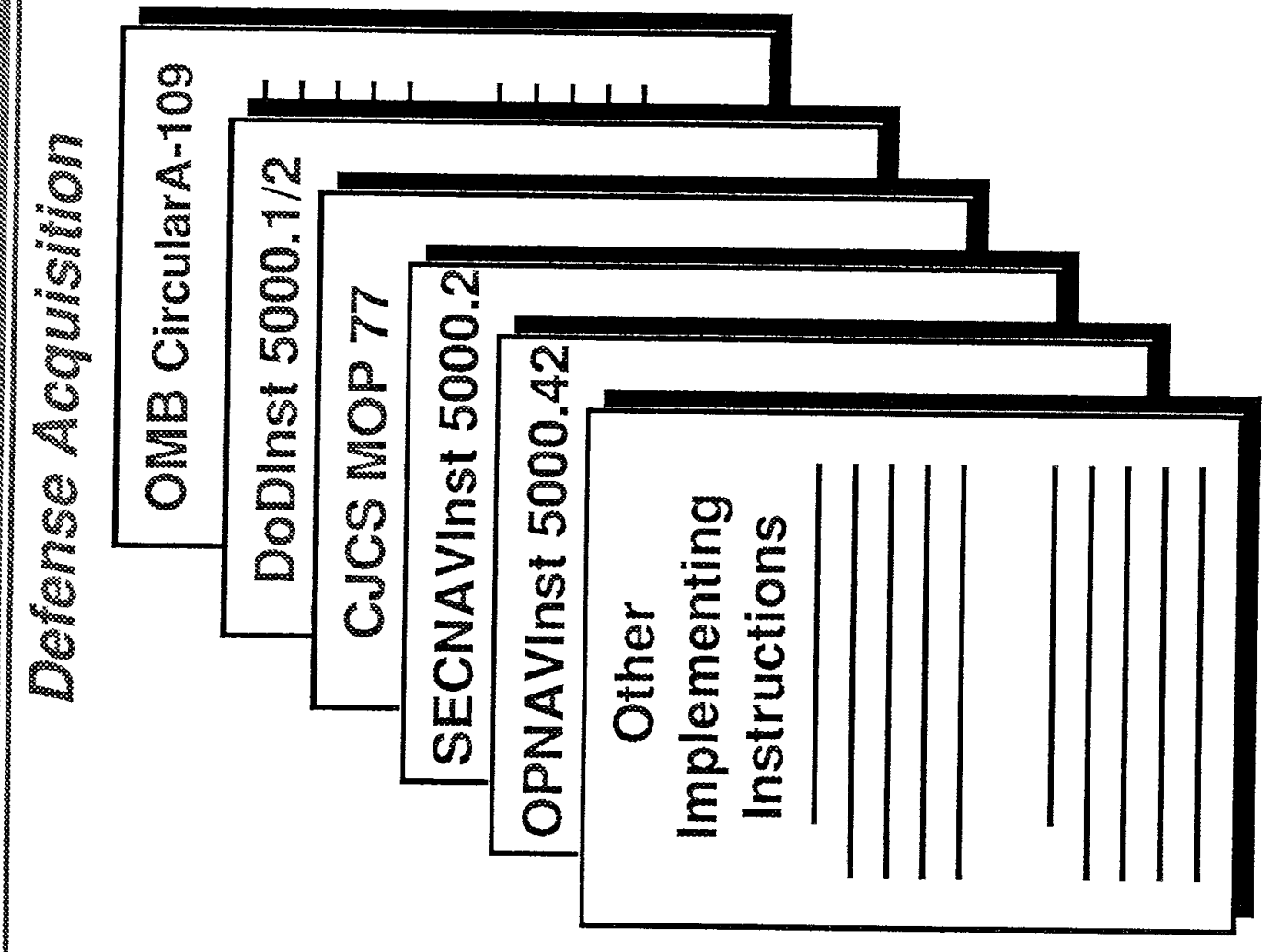

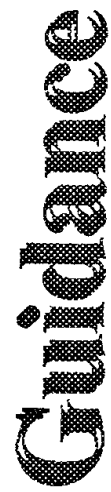






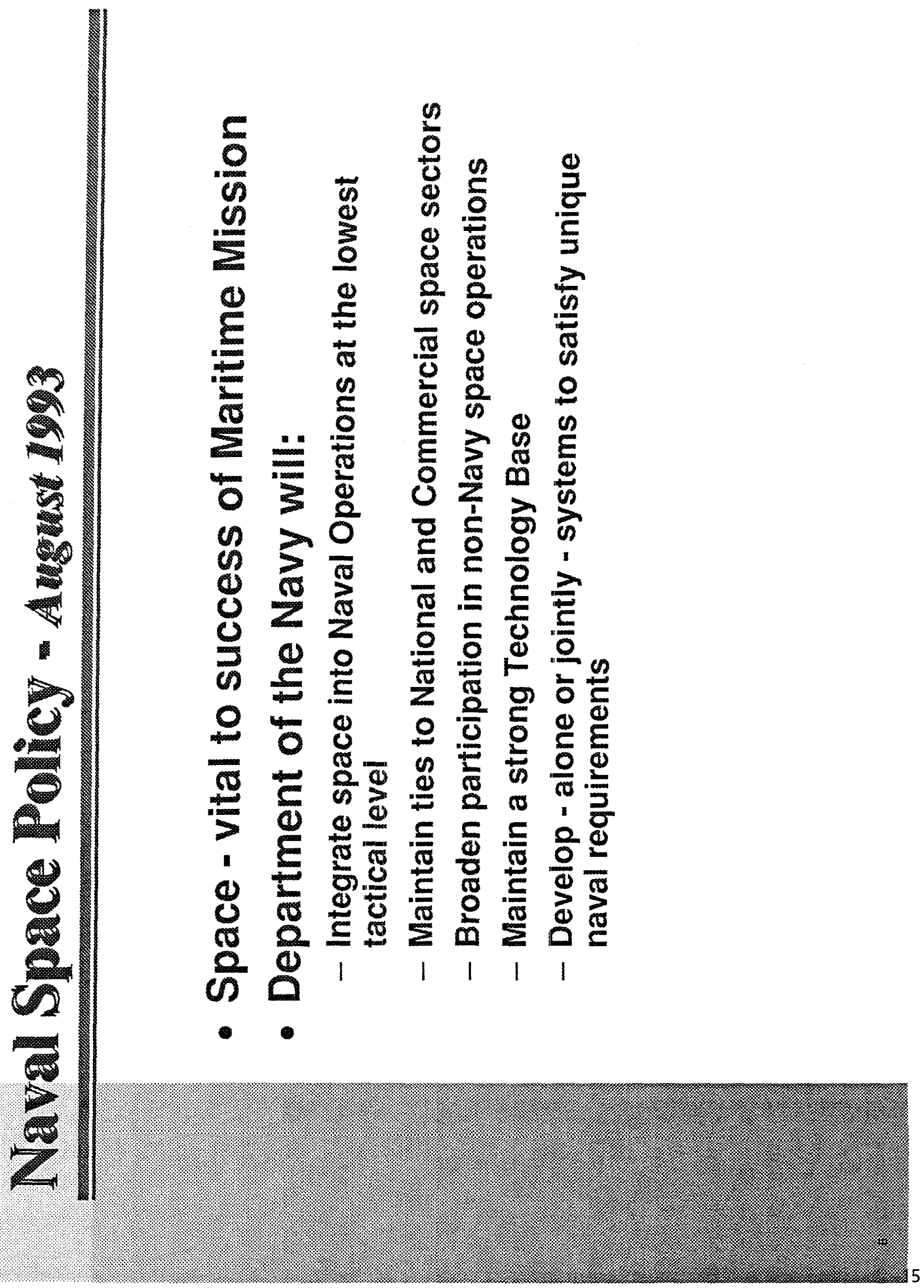




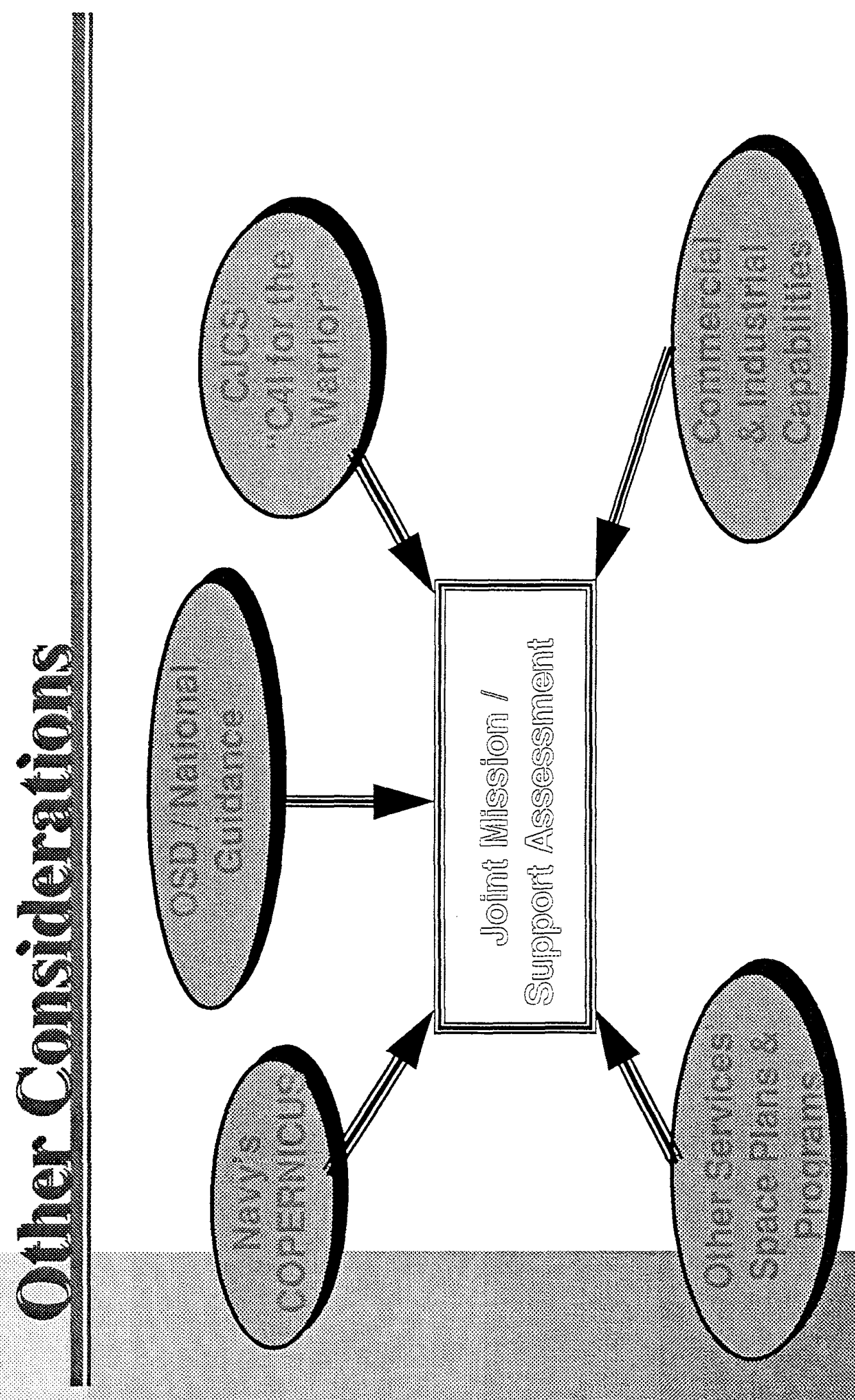




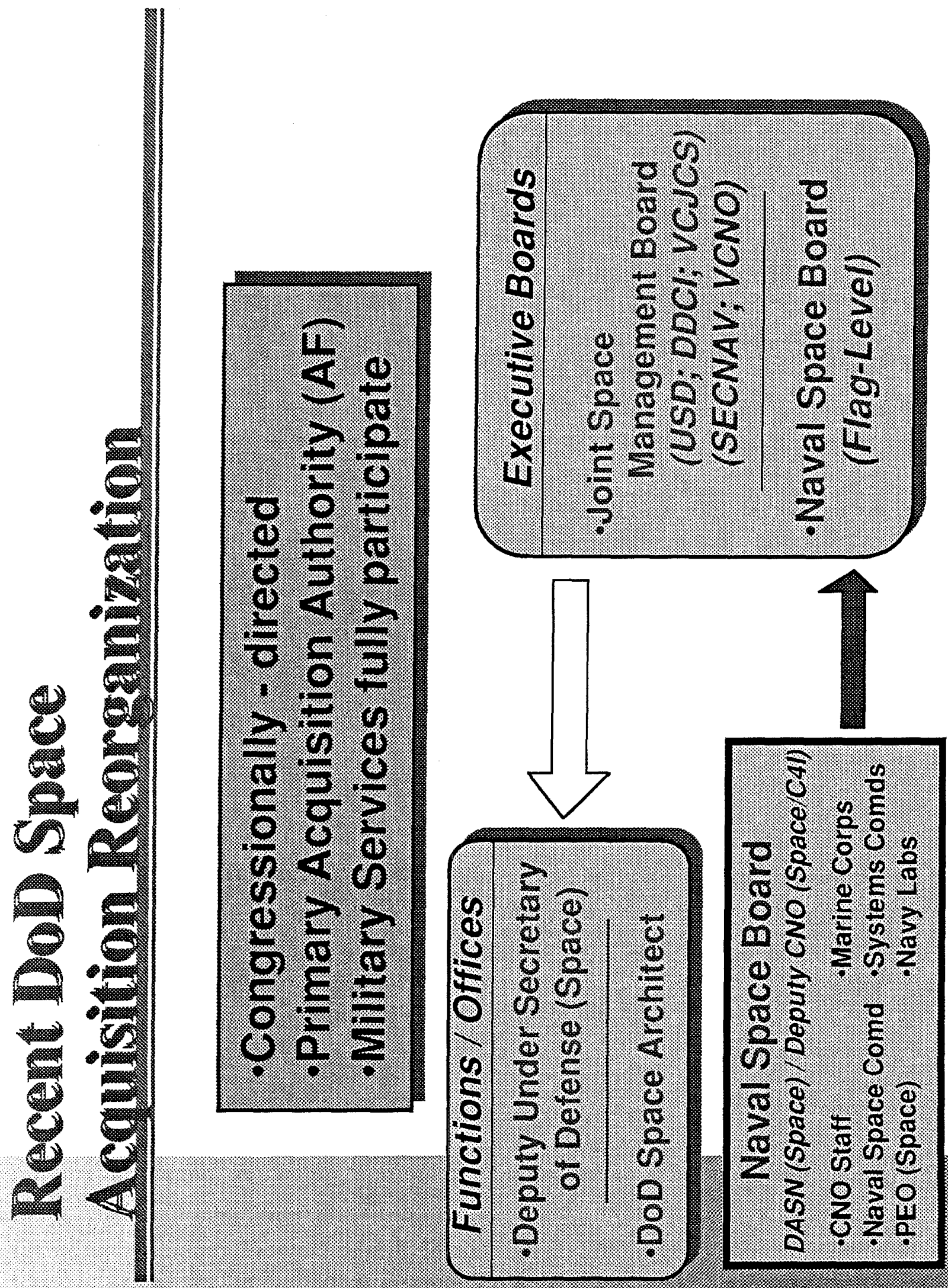




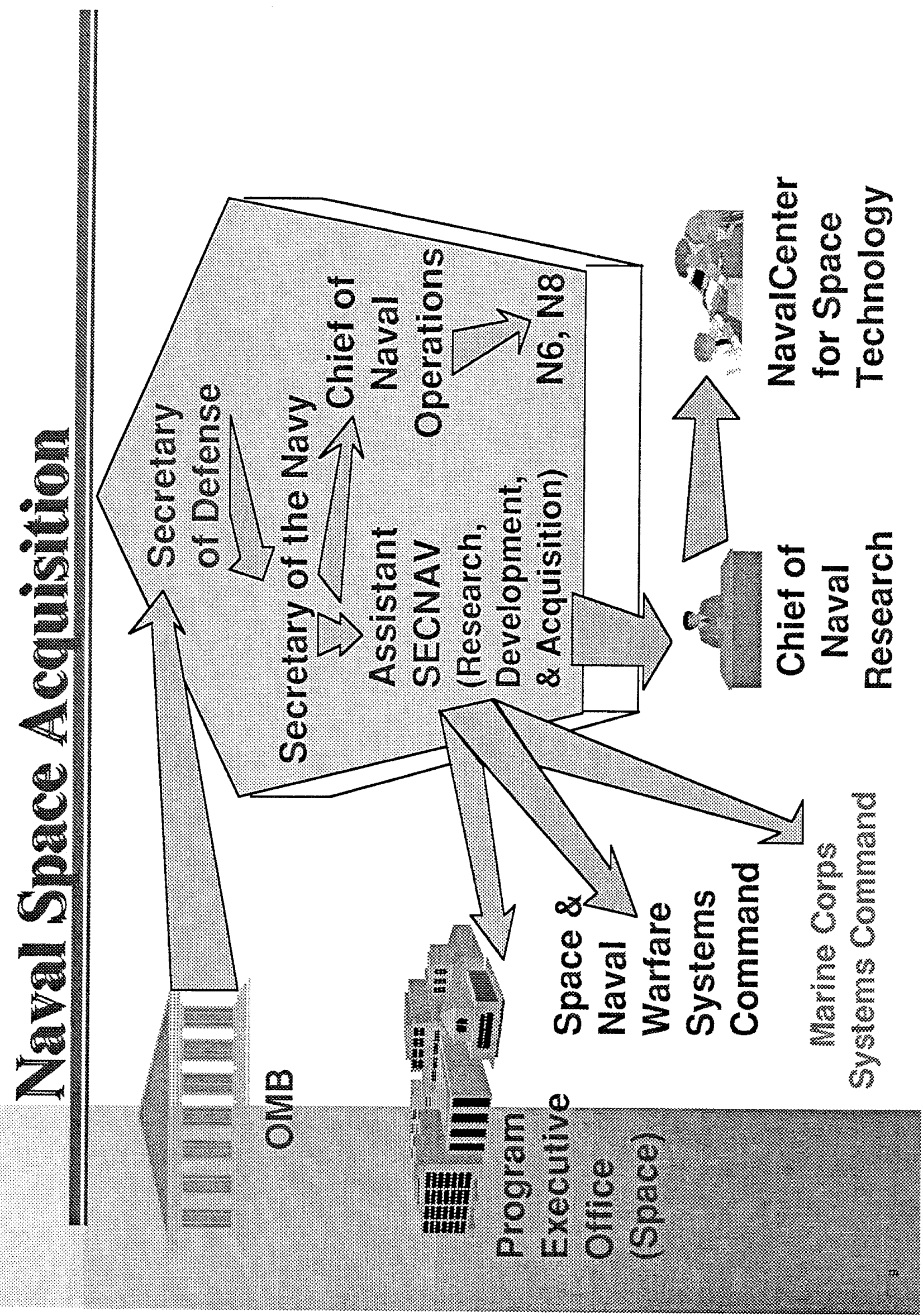









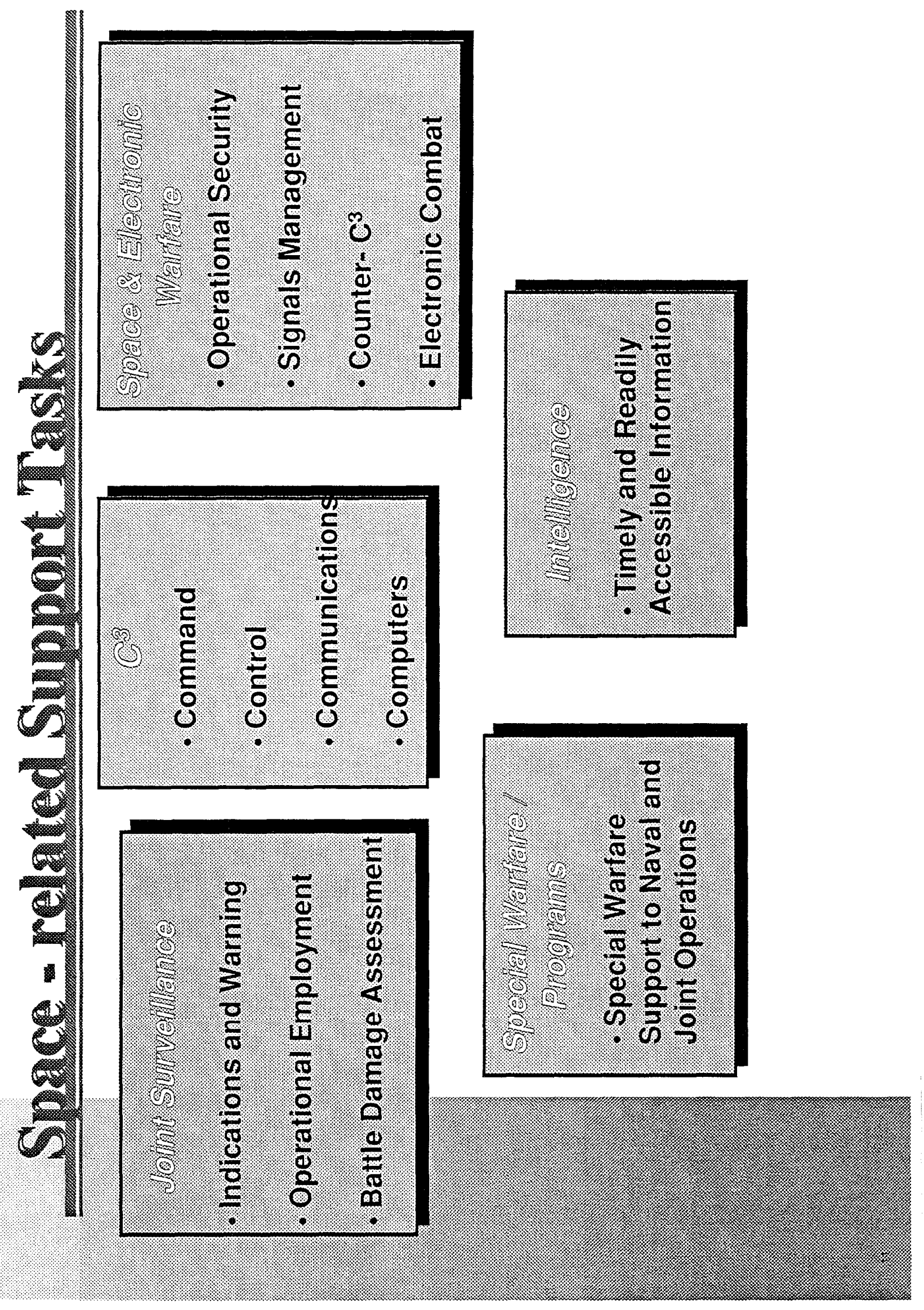




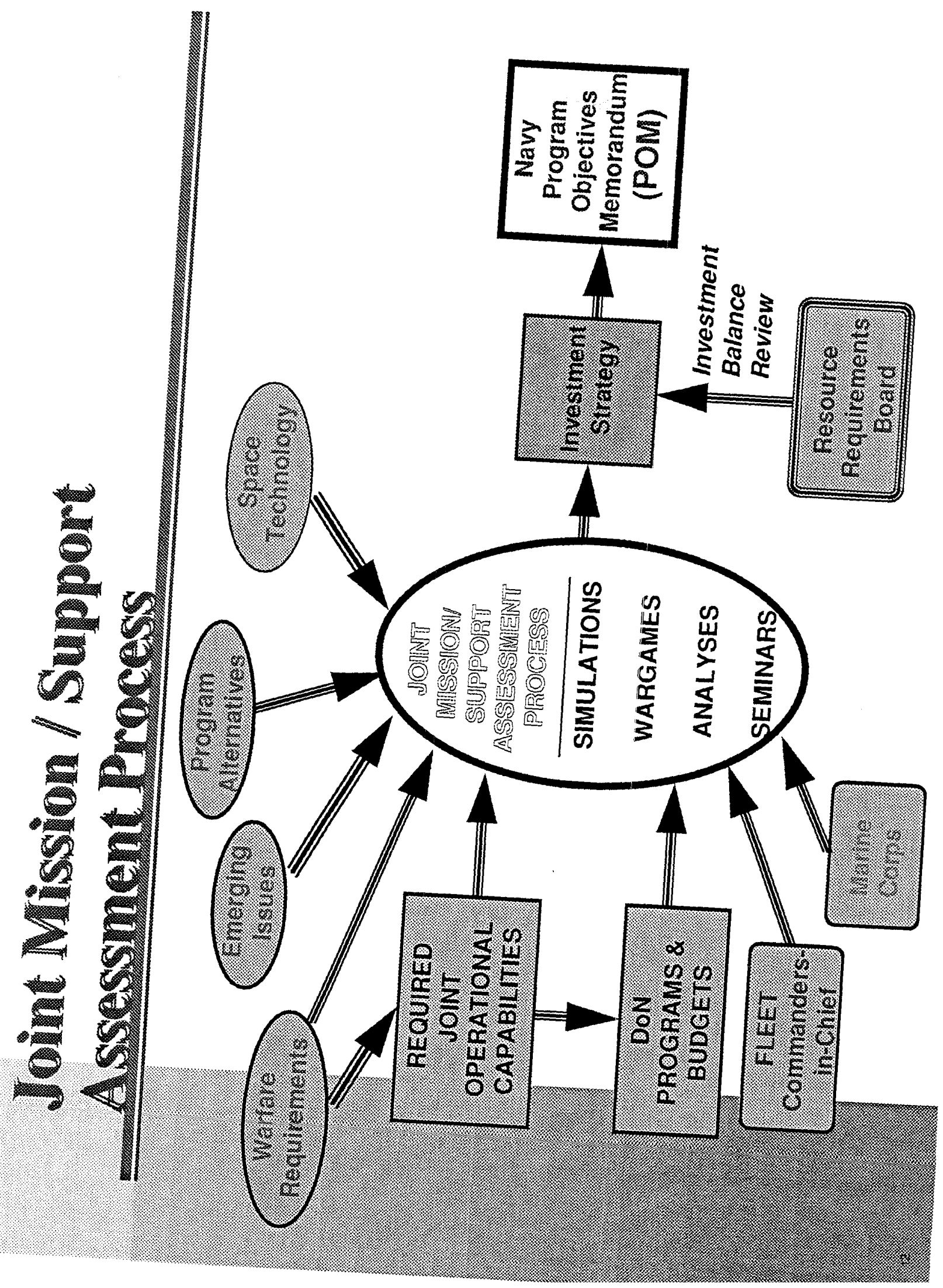









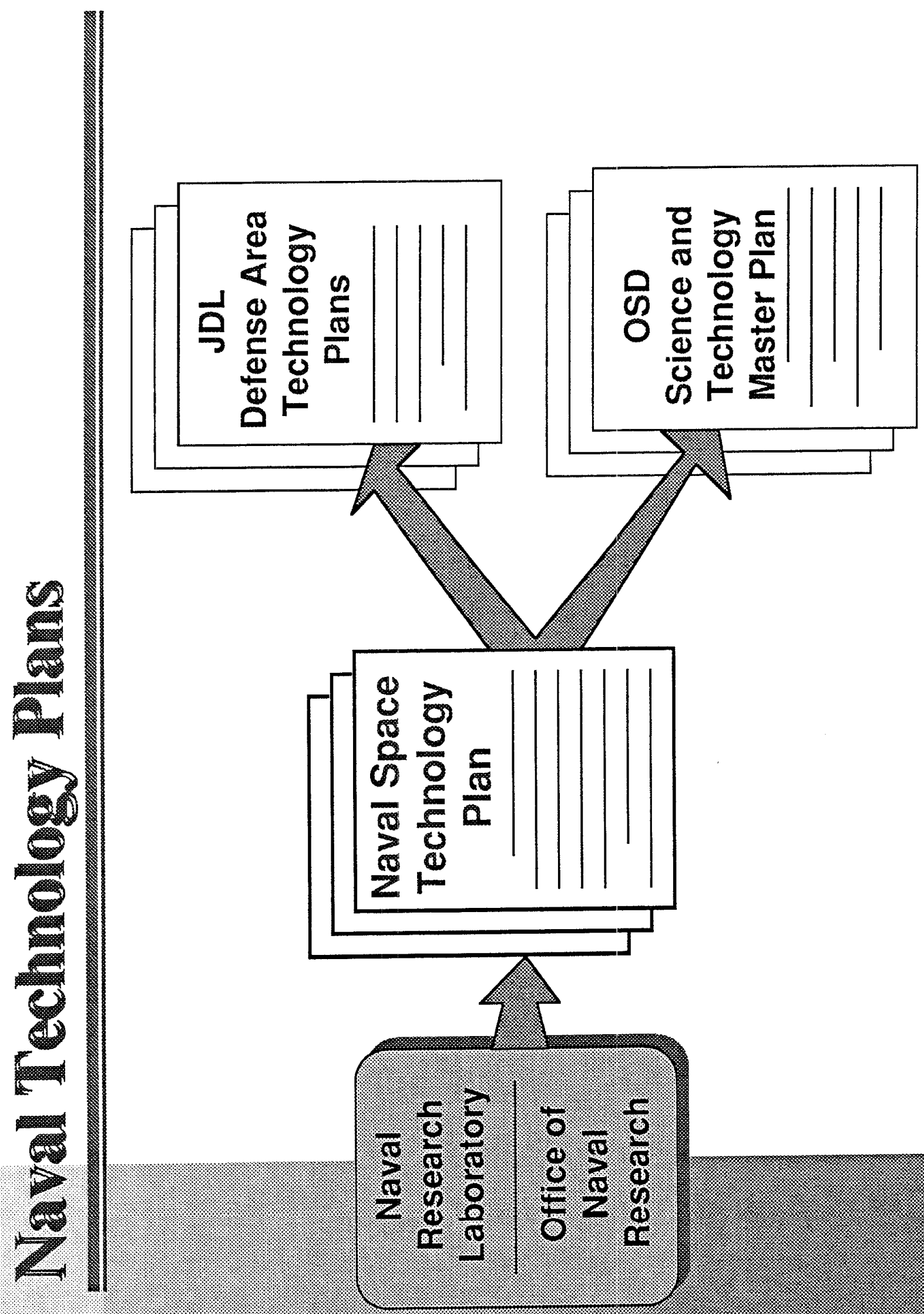









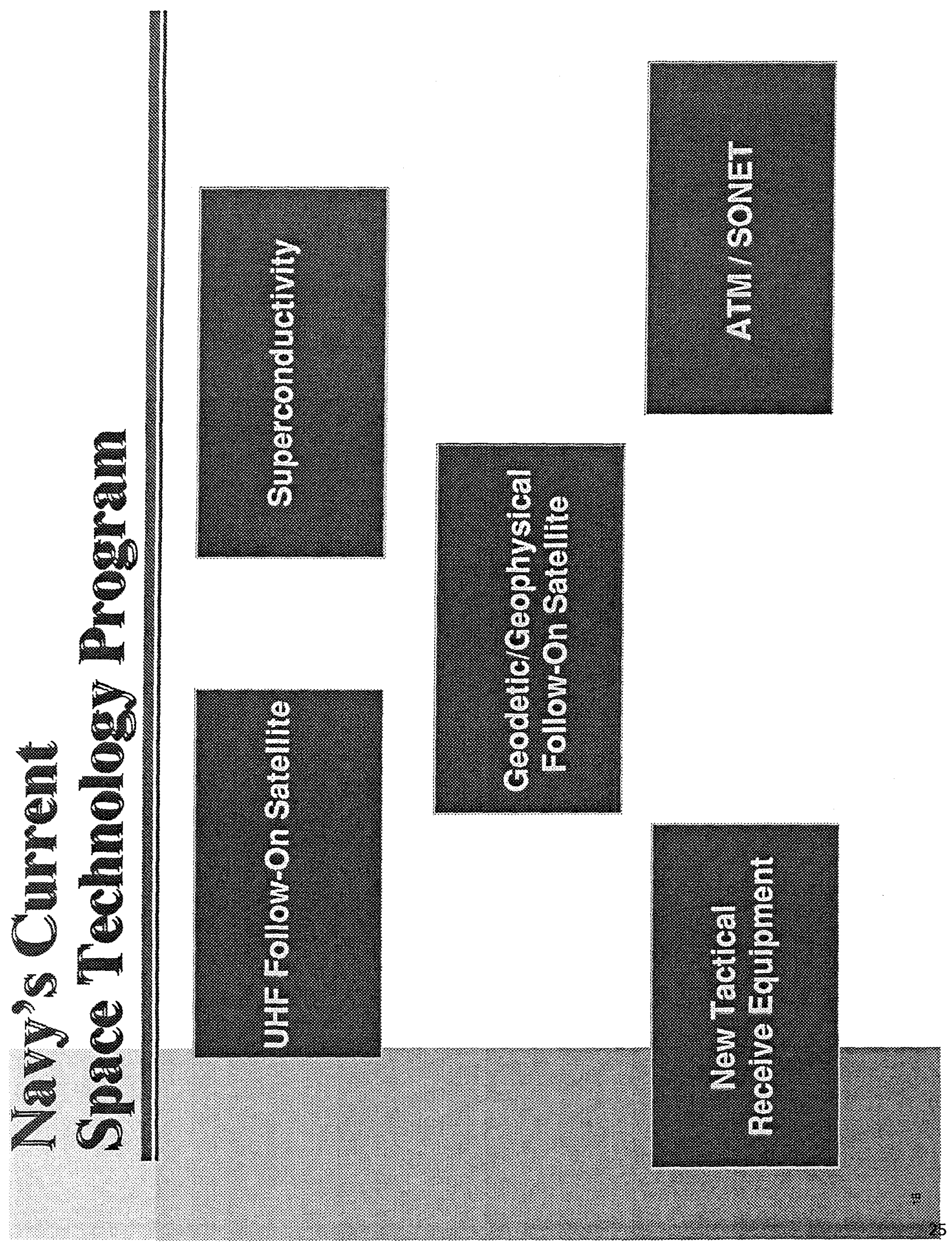




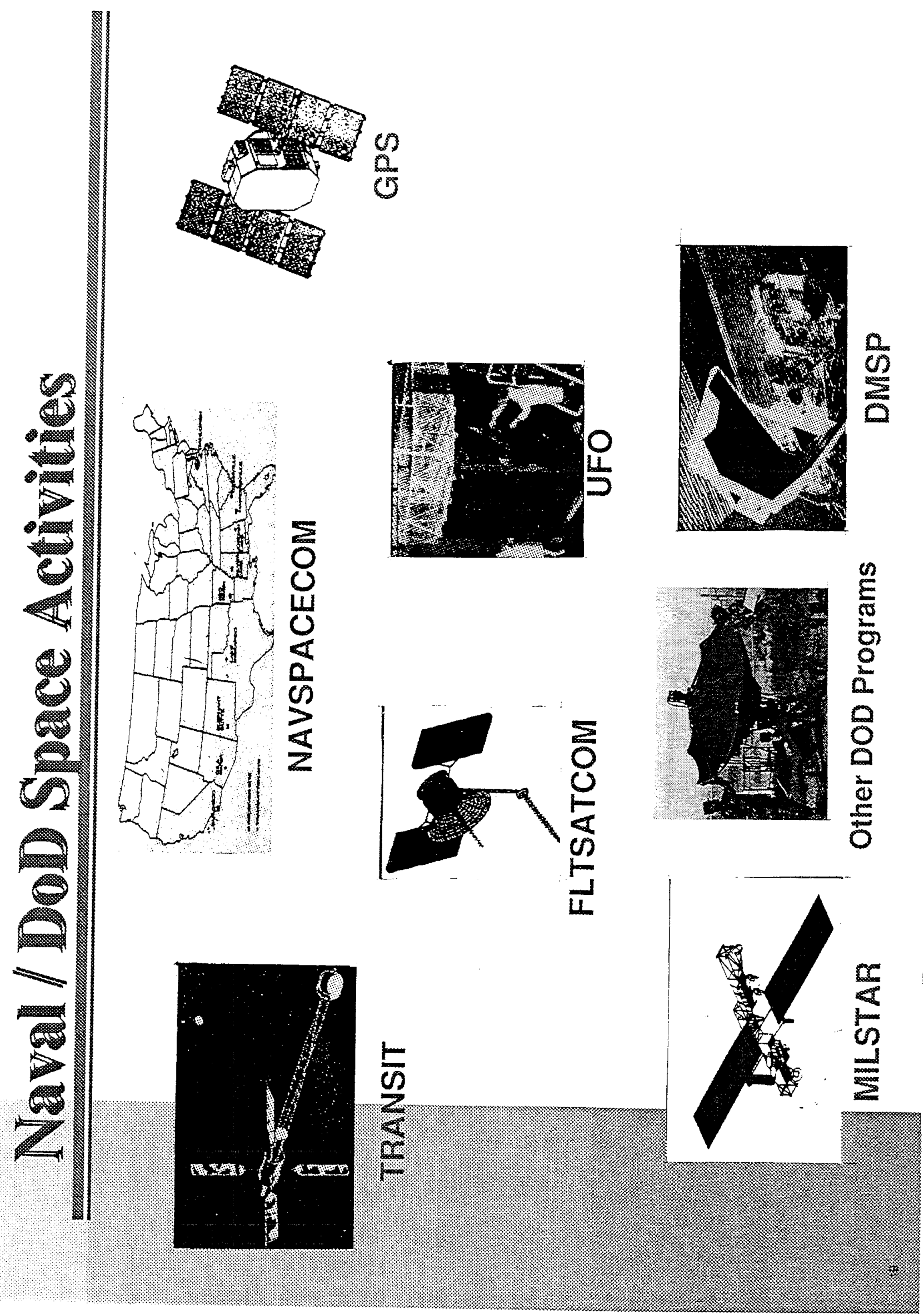




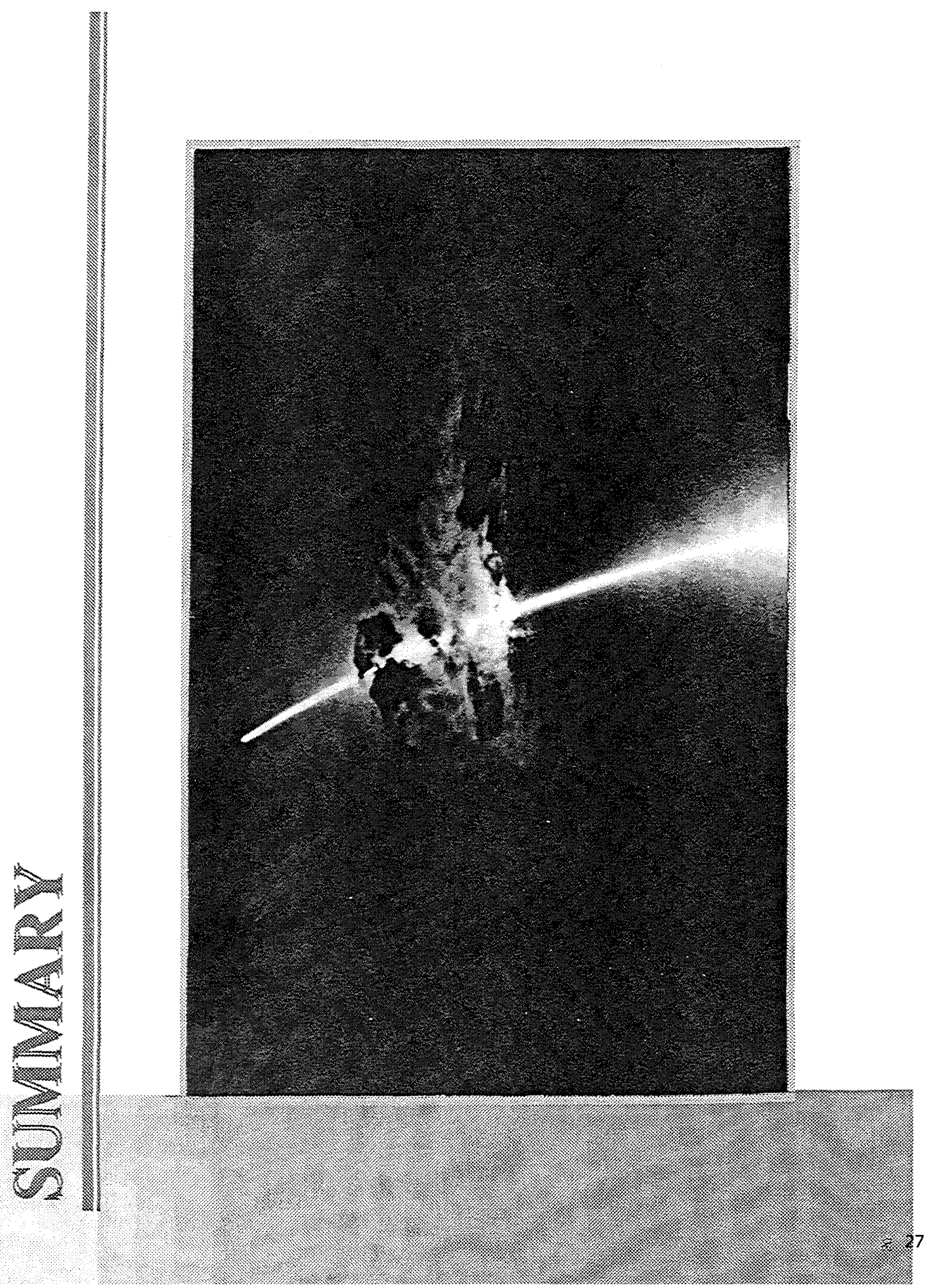

